Legislation to codify the change has already been introduced into both the House of Representatives and the Senate. It explicitly permits federal funding for research on stem-cell lines derived with parental permission from embryos left over at fertility clinics and otherwise slated for destruction. At least one observer has suggested that legislation explicitly approving federal funding for stem-cell research is needed to address the Dickey-Wicker amendment, a law first enacted by Congress in 1996 and renewed every year since, that prohibits federal funding of research in which embryos are created or destroyed (see Nature 457, 1068-1069; 2009).

Scientists and advocates say the change will speed up research on stem cells and the development of possible treatments around the world, and will help remedy what they see as the Bush administration's legacy of political interference in science. "This is the first time that the key decisions and guidelines on this issue are going to be made in Bethesda and not at 1600 Pennsylvania Avenue," says Larry Soler, executive vice-president of the Juvenile Diabetes Research Foundation International, based in New York City. "That is what the scientific community and the patient community have been asking for."

But there was a bittersweet taste to the victory, as scientists lamented almost a decade of delays to the research. "There's no doubt that this federal policy has really slowed the rate of progress of stem-cell research in the United
States, and the impact of the change in policy would have been greater if it had happened years ago," says Arnold Kriegstein, director of the Eli and Edythe Broad Center of Regeneration Medicine and Stem Cell Research at the University of California, San Francisco.

Those who oppose the research because it involves the destruction of embryos criticized Obama's decision. They say that the NIH should support research only on cells that are not derived from embryos, such as induced pluripotent stem cells (iPS cells), which are derived from adult cells but have many properties of embryonic stem cells.

But iPS cells, first created in 2006, are not a substitute for embryonic stem cells, Kriegstein says. "iPS technology and its ongoing improvement will likely eclipse embryonic stem-cell lines for diagnostic and therapeutic applications, but for now, embryonic stem cells are clearly needed. And it's still not clear how iPS cells will ultimately compare for therapeutic purposes."

Obama's action will begin to level the playing field for researchers in the United States, where some states - most notably California, which created the \$3-billion California Institute for Regenerative Medicine (CIRM) in $2004-$ have leapfrogged ahead of others by funding stem-cell research themselves. And it will have ripple effects around the world, some predict. "This type of science is international, and the whole world has suffered from the previous short-sighted and rather bizarre policy," says Robin Lovell-Badge of the National Institute for Medical Research in London.

For instance, Lovell-Badge collaborates on one project with NIH-funded scientists who have had to limit their work to the previously approved cell lines. More broadly, the lack of policy guidance from the NIH - normally a global science-policy leader - "has contributed to the morass of different rules adopted around the world, which in turn inhibits collaboration, goodwill and progress", Lovell-Badge adds.

Indeed, CIRM president Alan Trounson says that other nations with restrictive stemcell research policies, such as Germany, now seem to be rethinking their stance, and he predicts that the Obama administration's support for the research will accelerate this trend. Such support may also encourage wary investors and pharmaceutical companies to become more involved in funding the research, and this could benefit both the biotechnology industry and the development of new treatments.

"Since Obama was elected, the pharmaceutical industry is clearly much more interested in stem cells," Trounson says. "That will be a really big help when we're working through costly and difficult clinical trials to get treatments to patients."

\section{Erika Check Hayden}

See Editorial, page 125.

For more images of a US lab starting up stem-cell

work again, see http://tinyurl.com/avleu8.

\title{
Personalized cancer therapy gets closer
}

The long-awaited era of personalized genetic medicine may finally be arriving for people with cancer. Some cancer centres are preparing to screen all patients for genetic glitches associated with the disease, and scientists are starting to use detailed information about patients' tumour genomes to decide which treatments might benefit them most. "Oncology is absolutely farther down this road of personalized medicine than other areas," says Joan Scott, deputy director of the Genetics \& Public Policy Center in Washington DC.

Treatments that target specific mutant genes have been available for certain cancers since 2001, and a handful of studies have pinpointed mutations that reveal which tumours will respond best. For instance, mutations in the epidermal-growth-factor receptor (EGFR) gene affect how well patients with lung cancer respond to drugs that target the EGFR protein. But recent studies have highlighted the shortcomings of this one-gene-at-a-time approach by showing that the genetic roots of many cancers are both complicated and blurred: a wide variety of rare mutations can cause any one type of cancer ${ }^{1}$, and mutations in the same genetic pathways occur in many tumour types.

Last week, the Massachusetts General Hospital in Boston announced that it will carry out broad genetic testing of almost all patients with cancer, screening for $\mathbf{1 1 0}$ mutations in 13 cancer-related genes (see table, overleaf). Other hospitals are also moving in this direction: the Memorial Sloan-Kettering Cancer Center in New York City, for example, already tests 40 mutations in seven genes in all patients with lung or colorectal cancers. By picking up mutations in key genetic pathways, the tests could help oncologists to choose drugs that have been approved or are in clinical development. "In the next few years, I think every major cancer centre is going to work on this approach," says molecular pathologist John Iafrate of Massachusetts General Hospital.

Such advances are possible because the cost of genetic screening and sequencing technologies has been dropping precipitously. Hospitals can amplify and read out single altered 'letters' - or point mutations - in the DNA sequences of tumour genes commonly implicated in certain cancers. And academic researchers are a step beyond this, using high-speed sequencing to collect information about every gene in individual patients' tumours.

Last month, for example, Marco Marra, director of the British Columbia Cancer Agency's genome sciences centre in Vancouver, told attendees at the Advances in Genome Biology and Technology meeting 
on Marco Island, Florida, that his group had sequenced the whole genome of a tumour that had spread from one patient's mouth to his lung. The group had also used geneexpression studies to compare the activity of his tumour genes to those in healthy tissue.

They found that the patient had mutations in a tumour-suppressor gene called PTEN, and abnormally high expression of a gene downstream of PTEN, called RET. This explained why he had not responded to treatment with the drug erlotinib, and fits with some earlier studies suggesting that patients with active PTEN respond better to erlotinib ${ }^{2}$. Marra's team recommended instead that the patient be put on a drug called sunitinib, which inhibits the protein made by RET. The patient's cancer subsequently regressed.

"This work illustrates how one can potentially use next-generation sequencing technologies to establish the appropriate course of cancer treatment for individual patients," says Eric Green, scientific director of the National Human Genome Research Institute in Bethesda, Maryland.

Studies such as Marra's are being conducted in many patients to find genetic traits that could predict how tumours respond to treatment. And such studies are likely to increase as the cost of genome sequencing drops. Rick Wilson, director of the Genome Sequencing Center at Washington University in St Louis says that

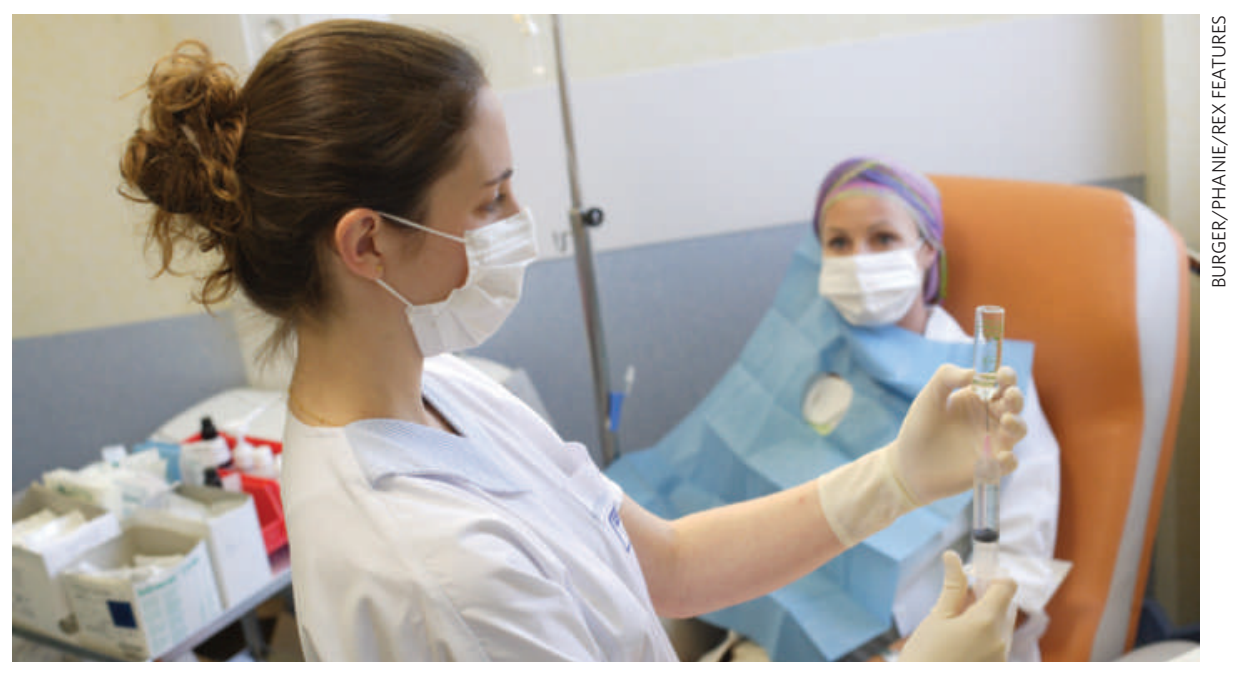

Some patients with cancer have gene mutations that can be targeted by specific drugs.

it cost more than $\$ 1$ million for his centre to sequence the first tumour genome last year ${ }^{3}$. He estimates that the second tumour genome sequenced at the university cost $\$ 500,000$, and projects that this could drop to $\$ 50,000$ per tumour by early next year.

Some businesses are finding that a handful of patients - who may already be paying thousands of dollars for their diagnosis and treatment - are willing to pay this sort of money for cancer-related genetic information. Last year, for example, a company called CollabRx, based in Palo Alto, California, began offering a service

\begin{tabular}{|ll|}
\hline PATIENT CANCER GENES UNDER SCRUTINY \\
\hline Gene tested (by whom) & Implicated in which major cancers \\
\hline APC (MGH) & Brain, colorectal, liver, stomach, thyroid \\
\hline Beta-catenin (MGH) & Brain, colorectal, liver, lung, ovarian, skin \\
\hline BRAF (MGH, MSKCC) & Colorectal, lung, skin, thyroid \\
\hline EGFR (MGH, MSKCC) & Lung \\
\hline FLT3 (MGH, MSKCC) & Blood \\
\hline JAK2 (MGH, MSKCC) & Blood \\
\hline KIT (MGH) & Blood, gastrointestinal, germ cell \\
\hline KRAS (MGH, MSKCC) & Colorectal, lung, pancreas \\
\hline NOTCH1 (MGH) & Blood \\
\hline NRAS (MGH) & Blood, colorectal, thyroid \\
\hline TP53 (MGH) & Anal, bladder, bone, brain, breast, cervical, colorectal, head and neck, liver, \\
\hline PIK3CA (MGH, MSKCC) & Brain, breast, colorectal, liver, lung, ovarian, stomach \\
\hline PTEN (MGH) & Blood, brain, breast, cervical, endometrial, head and neck, prostate, skin \\
\hline MEK1 (MSKCC) & Lung \\
\hline AKT1 (MSKCC) & Breast, colorectal, lung, ovarian \\
\hline HER2 (MSKCC) & Breast, ovarian \\
\hline MGH, Massachusetts General Hospital; MSKCC, Memorial Sloan-Kettering Cancer Center. \\
\hline
\end{tabular}

that analyses 15,000 genes, looking at gene expression, copy number and single-base mutations in individual patients' tumours for between $\$ 50,000$ and $\$ 100,000$. Five patients have used the service, which aims to determine which available drugs might be most suitable. Jay Tenenbaum, the company's founder and chairman, calls CollabRx's approach "personalized oncology research" because the results of each patient's individual analysis are used to help guide future analyses in other patients.

But because only a few drugs can currently be selected on the basis of specific mutations, "you have to be careful with raising expectations with that kind of approach", says Marc Ladanyi, chief of molecular diagnostics at the Memorial Sloan-Kettering Cancer Center.

Anna Barker, deputy director of the National Cancer Institute in Bethesda, is optimistic that treatment options won't stay limited for long. Genomic data being gathered from patients with cancer should help researchers to identify the genetic signatures that correlate with different symptoms or rates of disease progression and hence guide the development of drugs. Barker predicts that these signatures will also be used in the future to help doctors to combine existing drugs to target multiple genetic pathways and attack specific attributes of each patient's cancer. "I'm very optimistic that we can move in this direction, and it should be a more costeffective and better way of taking care of cancer patients," she says.

Erika Check Hayden

1. Check Hayden, E. Nature 455,148 (2008)

2. Mellinghoff, I. K. et al. N. Engl. J. Med. 353, 2012 (2005).

3. Ley, T. J. et al. Nature 456, 66-72 (2008). 